\title{
POBLAMIENTO RURAL EN EL TERRITORIUM DE ILICI: LA GRANJA ROMANA DEL CABEZO-Clot DE GalVANY (Elx, Alacant)
}

Situado en el territorium de Ilici, en el paraje de El Clot de Galvany (Elx), junto a un humedal de tierras pobres, presentamos una granja romana (ss. I-III d.C.). Su posición periférica respecto al área centuriada ilicitana, los restos materiales aparecidos (molinos, ausencia de estructuras de transformación, aislamiento relativo) y la gran simplicidad estructural y funcional del conjunto remarcan el carácter autosuficiente de este núcleo. El área arqueológica tras la época romana queda deshabitada y sólo volvió a frecuentarse a partir del s. XVII, coincidiendo con el crecimiento demográfico de época moderna, como muestra la construcción de una ermita. Todo ello nos lleva a plantear cuestiones relacionadas con la presión demográfica de época altoimperial y la caracterización de los asentamientos campesinos, no oligárquicos, de los territorios romanos.

Palabras clave: Granja romana, villa, Ilici, Clot de Galvany, Augusto, poblamiento rural.

\section{Rural Settlement in the Territorium of Ilici: The Roman Farm of The Cabezo-Clot de Galvany (Elx, Alicante)}

We present a Roman farm (1st to 3rd century AD) located in the natural park of The Clot de Galvany (Elx), next to a wetland of poor soils. Its peripheral location with respect to the centuriated area in Ilici, the material remains that have been found (mills, absence of transformation structures, relative isolation) and the remarkable structural and functional simplicity emphasize the self-sufficient character of this settlement. The archaeological area was abandoned after the Roman period and it was occupied again from the 17th century, coinciding with the population growth in Modern age, as evidenced by the building of a chapel. All these lead us to raise questions concerning the demographic pressure in Early Imperial period and the characterization of non-oligarchic peasant settlements of the Roman territories.

Key words: Roman farm, villa, Ilici, Clot of Galvany, Augustus, rural settlement.

La sociedad romana responde a un modelo claramente oligárquico-campesino en el que una pequeña parte enriquecida acumula el excedente, mientras que la mayor parte de la población campesina disfruta unos niveles modestos de vida, dejando escaso margen para unas reducidas y frágiles clases medias relacionadas con los sectores artesanos y comerciales. Las poblaciones campesinas productoras de bienes primarios (básicos o mínimamente transformados), que serán comercializados por otros agentes económicos (mercatores, nauicularii, negotiatores), presentan limitados, aunque proporcionalmente apreciables, niveles de consumo de bienes comerciales. Consecuentemente las cotas de participación de las clases bajas, la mayor parte de la población, en el reparto de los excedentes fueron reducidas, a diferencia de lo que ocurre en las sociedades de clases medias, entre las que no se encontraba la romana. Siendo así, ¿cómo podríamos explicar que los modelos de referencia de vivienda 


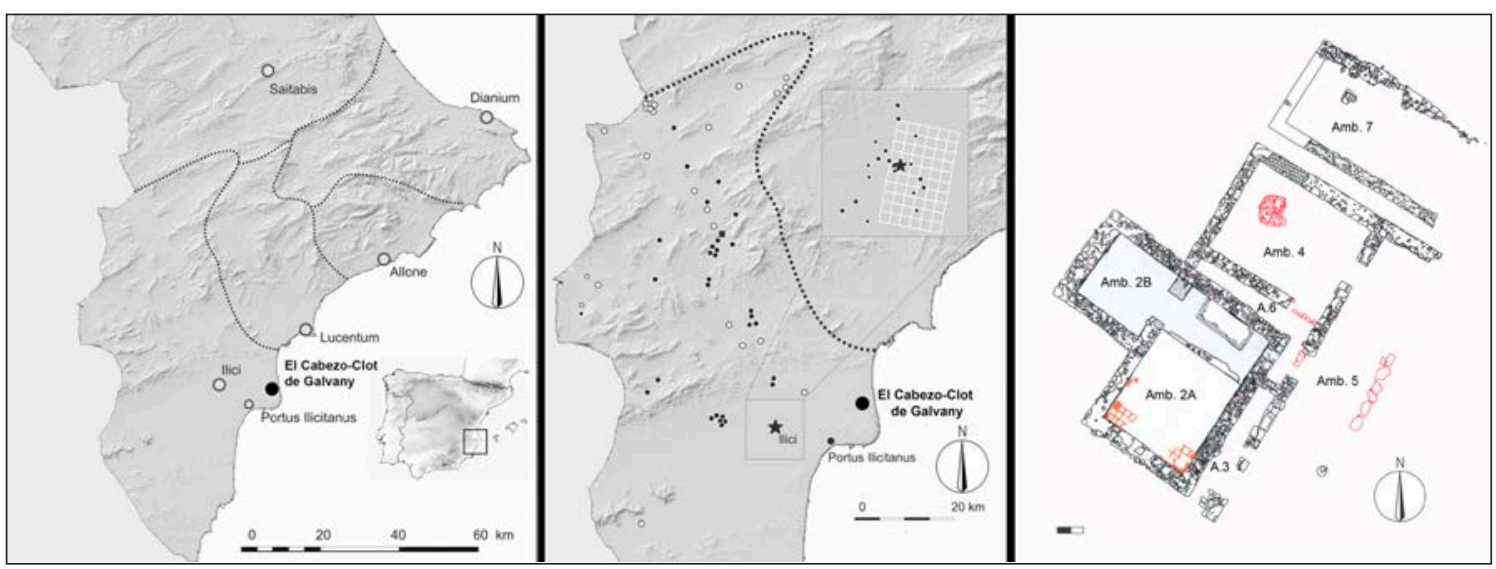

Fig. 1. Plano general de situación/ Área de excavación.

romanos sean la domus en ámbito urbano y la villa rustica para el rural? Sabemos que sólo las oligarquías ocupaban estas viviendas con un esquema axial y simétrico que busca la perspectiva o la articulación de espacios a partir del núcleo atrium-allae-tablinum. Sólo la oligarquía necesita o puede permitirse viviendas con múltiples dependencias de servicio, estructuras de representación social o complejos termales privados. Mientras que la mayor parte de la población no va a necesitar distinguir ámbitos públicos o privados en sus viviendas, puesto que no tienen vida pública, ni pretenden tenerla. Por todo ello hemos de cuestionar el valor de la representación pública en grupos sociales subalternos, dependientes o que, en general, rondaban los niveles de la subsistencia. En estos casos la casa se convierte en un verdadero hábitat privado de características básicas en la que el canon vitruviano queda adulterado y la uenustas o la firmitas quedan anuladas por la utilitas (Molina 2013:138).

Coherentemente hemos de plantear la pregunta que, en el marco de nuestras investigaciones del territorium de Ilici, nos animó a emprender la excavación del yacimiento de El Cabezo-Clot de Galvany-Elche, Alicante). ¿Dónde vivía la mayor parte de los campesinos romanos ilicitanos? Un primer impulso, vinculado con los planteamientos historiográficos tradicionales, nos llevaría a señalar las villae rusticae. Pero, desde nuestro punto de vista, este modelo de referencia de origen itálico, habríamos de asimilarlo a núcleos con una orientación productiva preferentemente comercializadora. Por ello, este tipo de yacimientos los encontramos en áreas bien comunicadas (cercanas a centros de distribución o polos de comunicación) y nos aportan evidencias materiales de la existencia de cultivos transformables y comercializables como la vid o el olivo (cellae uinariae, torcularia, hornos) (Molina 2009: 45). Como veremos a continuación nada que ver con lo que encontraremos en el yacimiento de El CabezoClot de Galvany.

Entonces ¿por qué apenas tenemos constancia material de las viviendas o espacios agrarios ocupados por la mayor parte de la población, los campesinos? Existe un elemento de carácter historiográfico básico que se refleja en buena parte de los planteamientos interpretativos de la arqueología tradicional: la investigación histórica tradicional tiene un marcado carácter oligárquico. Porque los historiadores, muy vinculados social y culturalmente al ámbito de las elites hasta hace unas décadas, se centraban en problemas y temas con los que se identificaban. Otro factor importante es el propio carácter oligárquico de las fuentes escritas que ignora, en buena parte, los temas y referencias a las clases sociales inferiores, y aún más a las estructuras productivas, en general, y a las habitativas campesinas en particular. A ello habríamos de añadir una similar orientación elitista de la denominada "arqueología filológico-romántica” que ha llegado hasta nuestros días, centrada en el hallazgo de estructuras monumentales que ilustraran los modelos aristocráticos que nos describían las fuentes escritas. Todo ello explicaría la indiferencia despertada por las viviendas y estructuras productivas más populares de escasa monumentalidad y que, por otra parte, dada la menor calidad de sus materiales constructivos y, consecuentemente, su mayor degradación y peor conservación, eran más difíciles de detectar o más fáciles de eliminar en ámbitos poco asequibles para la protección del patrimonio. 
Estamos en el territorio de la Colonia Iulia Ilici $\mathrm{Au}-$ gusta en el paraje natural de El Clot de Galvany (Elx) un humedal litoral aislado del mar por un conjunto de arenales fósiles y restingas arenosas que rodean el cabo de Santa Pola. Antes de las bonificaciones modernas, el paraje estaría unido al humedal de las Salinas de Santa Pola, e incluso actualmente en temporadas altamente pluviales queda comunicado con éste. La aparición a los pies de El Cabezo-Clot de Galvany de restos arqueológicos superficiales de épocas antigua y moderna despertó la atención sobre este núcleo y desató interpretaciones poco fundamentadas. Las primeras noticias sobre la existencia de un yacimiento arqueológico proceden de A. Sáez Llorens, quien informa a R. Ramos Fernández, antiguo director del Museo Arqueológico Municipal de Elche, que realiza una prospección superficial en 1981 que sirve para su catalogación. El yacimiento es descrito como gran emplazamiento urbano de época romana con depósito de garum, de adscripción romana y cronología de los ss. I al IV d.C. y queda así incluido en el PGOU y, posteriormente, en el Inventari de Jaciments Arqueològics de la Conselleria de Cultura, Investigació, Educació i Ciencia de la Generalitat Valenciana.

En 2007 desde la Universidad de Alicante encabezamos un proyecto junto a B. Carrillo López, C. Frías Castillejo y F. Llidó López con la finalidad de delimitar y excavar este yacimiento en el marco de nuestras investigaciones sobre las estructuras de poblamiento y producción de la Colonia Iulia Ilici Augusta. Después de la fase de prospecciones (2007) se desarrollaron dos campañas de excavaciones (2008 y 2009), y una de restauración y puesta en valor (2014). Tras la excavación del yacimiento se individualizaron tres ámbitos de ocupación claramente diferenciados: un asentamiento campesino de época romana, objeto preferente de este trabajo ${ }^{1}$; una ermita del s. XVII que se le superponía, y un tercer conjunto aislado identificado como una balsa para el tratamiento del esparto de época moderno/contemporánea. La realización de una serie de sondeos (S1-4) complementarios en la periferia de las estructuras descartó la existencia de otros restos constructivos.

\section{LAS ESTRUCTURAS ARQUEOLÓGICAS NO RO- MANAS}

En la parte más meridional del yacimiento, junto al camino del Carabassí, se halla una estructura cuadrangular que excavaciones o expolios previos habían dejado prácticamente al descubierto, como indican las marcas recientes de pico en el mortero y los restos de vidrio moderno y plástico aparecidos en el fondo. Se trata de una balsa rectangular de 9,25 x 8,80 m delimitada por muros de mampostería trabada con cal de $0,80 / 0,90$ m de anchura. El pavimento es de mortero de cal de color grisáceo ligeramente inclinado hacia el sur, con una diferencia de cota de 0,10 m y tiene una preparación de piedras pequeñas y fragmentos cerámicos trabados con mortero.

En los extremos del muro meridional de la balsa (UE 5), apoyadas en su cara exterior se encuentran dos estructuras rectangulares de piedra trabadas con mortero de cal (UE 34: 0,80 x 0,80 y UE 56: 1,35 x 0,85 m), con funciones

Fig. 2. Planta general de ac-

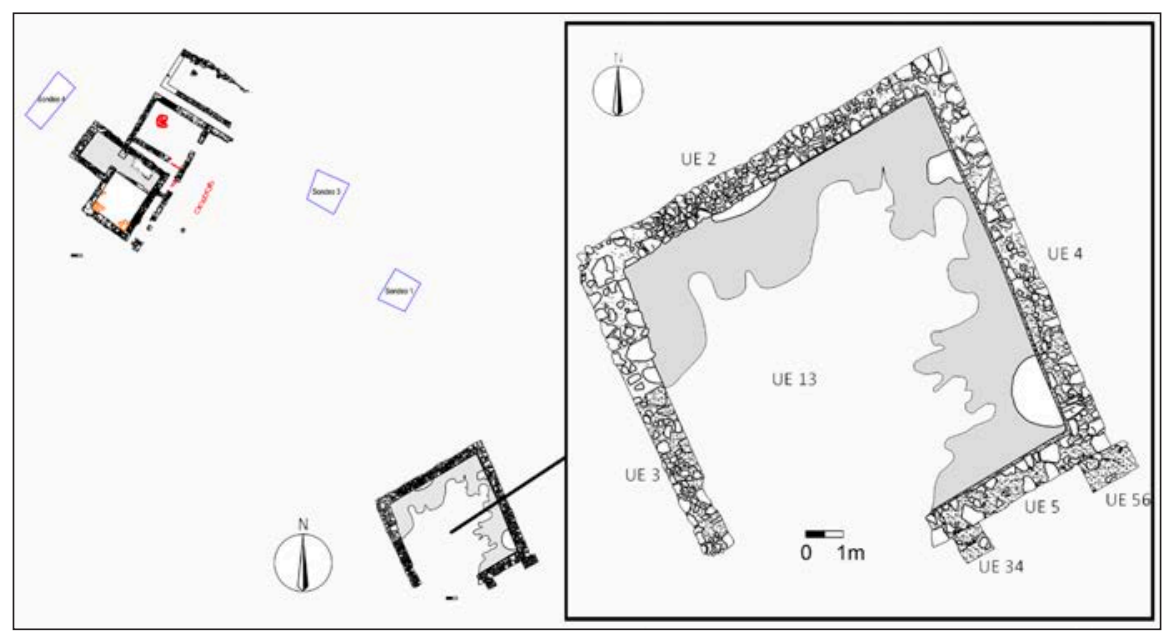

tuaciones y balsa moderna. 

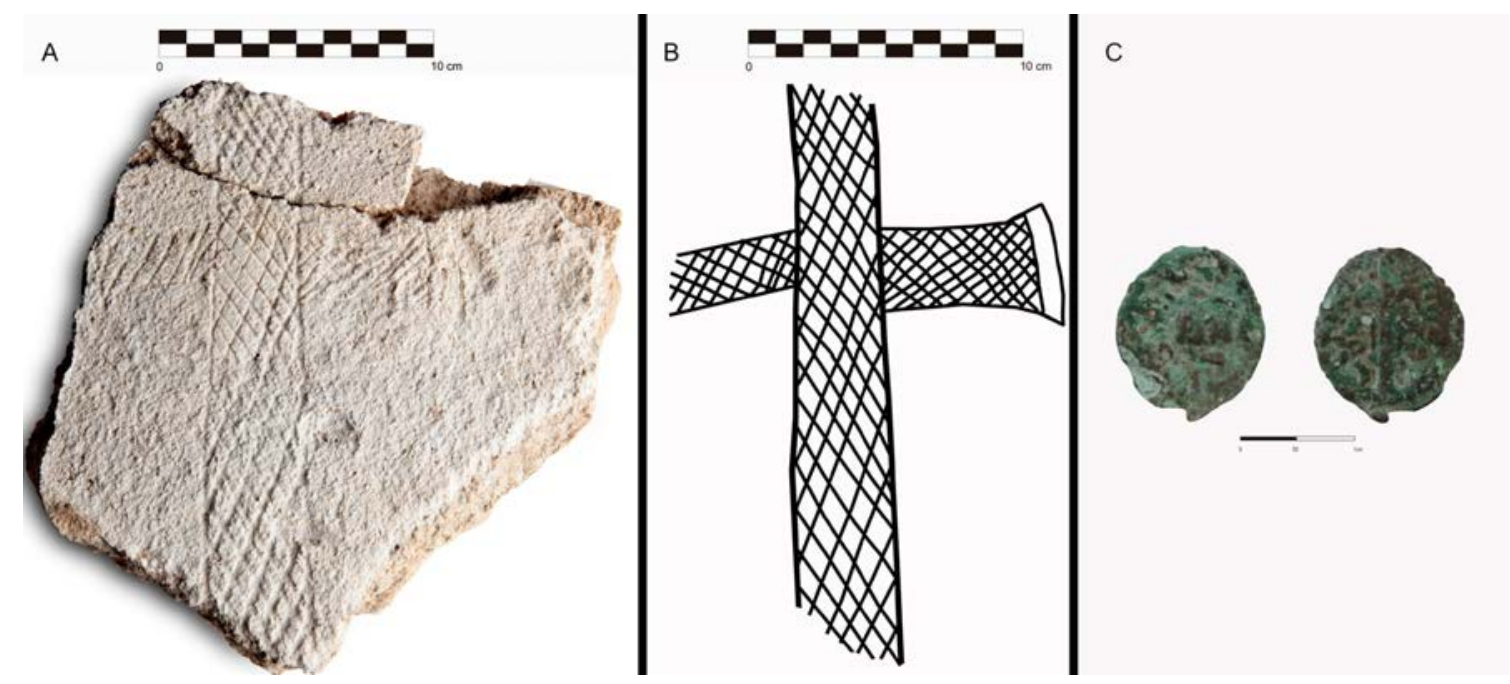

Fig. 3. Restos destacables de la ermita del siglo XVII: A) fotografía de cruz incisa en el enlucido de las paredes interiores de la ermita; B) dibujo de la cruz; C) Diner menut (UE 107).

de contrafuertes del lado que soporta más tensiones debido a la inclinación del terreno. La excavación de la fosa de fundación (UE 41) del muro meridional recortada en la roca natural hallamos fragmentos de cerámica de época romana y moderna-contemporánea. Se acumulan los elementos que descartan su adscripción antigua: las molduras y enlucidos de los ángulos presentan forma cóncava y no coinciden con la característica moldura de media caña romana, y el revestimiento superficial de la balsa no es el característico opus signinum hidráulico romano. En cualquier caso, los contextos estratigráficos son concluyentes sobre la adscripción moderna-contemporánea de la balsa: la preparación del pavimento (UE 12) está compuesta por piedras pequeñas y fragmentos cerámicos con pastas y formas de época moderna-contemporánea; el relleno de la fosa de fundación UE 42 contenía varios fragmentos de cerámica clara africana $\mathrm{C}$, común africana y TS hispánica, pero también bastantes restos de paredes de cerámica vidriada de difícil adscripción (probablemente de los ss. XVII a XIX); el abandono de la estructura se puede fechar en el s. XX, a partir de varios fragmentos cerámicos procedentes de los derrumbes (UE 8 y 30). En definitiva esta estructura es una gran balsa de época modernacontemporánea, cuya función podría estar relacionada con el trabajo del esparto, muy abundante en este paraje, lo que daría sentido al pozo aledaño.

Más destacable es el pequeño edificio con doble estancia (Amb. 2 A y B), estratigráficamente superpuesto a la granja romana, que hemos identificado como una ermita.
Presenta una estancia o nave principal (2A) de planta rectangular $(4,60$ x 6,60 m) y doble nivel de pavimentación separado por un escalón, que interpretamos como el nivel elevado del presbiterio, remarcando el carácter religioso del edificio. Al NO de la nave principal se abre una estancia adyacente de pequeñas dimensiones $(4 \times 3,75 \mathrm{~m})$ con pavimentación de mortero de cal (UE 92). Adosado al muro del fondo (UE 18), localizamos un estrato de tendencia horizontal $(1,60 \times 0,70 \mathrm{~m})$, compuesto por mortero de cal con dos hendiduras semicirculares en los extremos (UE 138), que podrían servir como base para dos postes que formarían parte de una estructura. Esta estancia lateral (Amb. 2B) muy probablemente fuera la sacristía, aunque en otros contextos se interpreta como la casa del ermitaño o santón.

Presenta un único acceso (UE 117) orientado al SO, abierto hacia el camino del Carabassí y en el lado opuesto se dispone de forma axial una estructura rectangular (UE 94), que relacionamos con lo que sería un altar, construido sobre el presbiterio. El pavimento de la parte principal de la nave está realizado con losetas cerámicas de 0,23 $\mathrm{m}^{2}$ (UE 103-107), unidas entre sí con mortero, mientras que mucho más arrasado no se hallan restos de éstas ni en el presbiterio ni en la sacristía, que presentan pavimentación de mortero de cal (UE 92).

Sobre el pavimento de losetas (UE 107) apareció una moneda que nos permitiría contextualizar el momento de uso/abandono del edificio. El extraordinario deterioro del anverso de la moneda impide ver el rey que aparece, pero el reverso permite determinar que se trata de un diner 


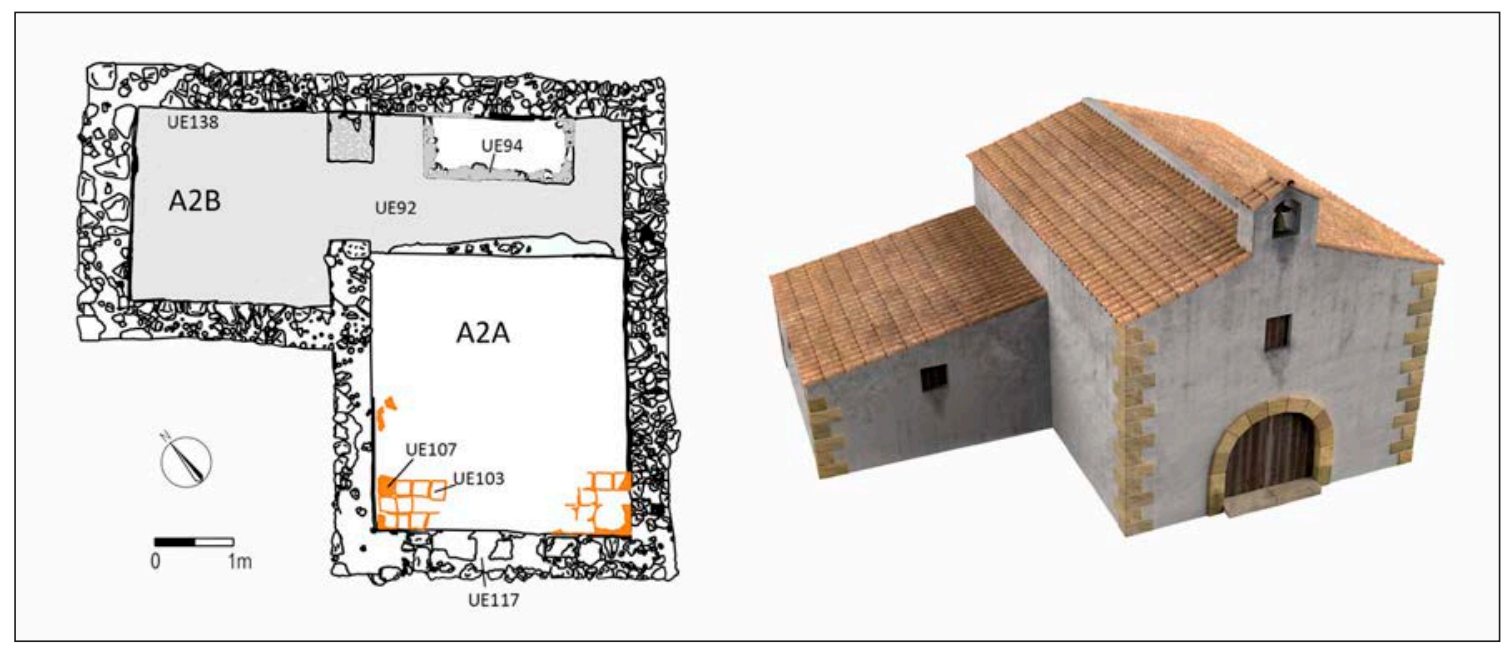

Fig. 4. Ermita del s. XVII: planta y reconstrucción virtual (realizada por J. Molina y D. Tejerina).

menut de la ceca de Valencia y, por tanto, del s. XVII. Entre los restos de relleno/derrumbe del edificio han aparecido distintos fragmentos de enlucido de cal de color blanco, algunos decorados con franjas y motivos de color rojo. Entre ellos cabe destacar un fragmento del enlucido que presenta una cruz incisa de $17,7 \mathrm{~cm}$ de alto por 11,6 $\mathrm{cm}$ de ancho.

El edificio cabe datarlo en el siglo XVII por el hallazgo monetario hallado en contexto fiable y por la presencia de la sacristía, un elemento que aparece en las ermitas rurales a partir de finales del siglo XVI o principios del XVII (Gutiérrez-Cortines y Griñán 1994: 59).

\section{LA GRANJA ROMANA DEL CABEZO-CLOT DE GALVANY}

Estratigráficamente por debajo de las estructuras de la ermita hallamos un edificio de planta rectangular con orientación N-S, parcialmente arrasado por ésta en su lado meridional. Se trata de un edificio de estructura rectangular $(12,6 \times 8,75 \mathrm{~m})$ compuesto por tres estancias (Amb. 4: 4,9 x 3,75 m (18,11 m²); Amb.6: 4,9 x 2,52 m $\left(12,25 \mathrm{~m}^{2}\right)$; Amb.3: 4,9 x 4,2 m $\left(19,49 \mathrm{~m}^{2}\right)$ y un pórtico o porche longitudinal (Amb. 5: 2,16 x 12,15 m (27,44 $\left.\mathrm{m}^{2}\right)$, que ocupaba parte de la fachada orientada a levante. Al norte del conjunto, y apenas separado $0,65 \mathrm{~m}$, encontramos otro edificio rectangular (Amb. 7: 3,98 x 7,83 m $\left(20,09 \mathrm{~m}^{2}\right)$ con orientación E-O, del que sólo se conservan los niveles de cimentación, debido a la fuerte erosión del terreno, y cuya función es difícil de determinar aunque parecería tener funciones auxiliares a las del hábitat (almacén, cobertizo o cuadra).

Los muros presentan anchura desigual con una tendencia media de $0,50 \mathrm{~m}$ de amplitud y están realizados en algunos tramos con mampostería a doble paramento trabada con mortero de cal y piedra de pequeño y mediano tamaño $(20$ x $15 \mathrm{~cm})$. Se alternan los tramos en los que el mortero de cal es evidente con otros en los que se ha perdido o estuvo menos presente. Destaca la existencia de refuerzos en los ángulos con sillares o bloques de piedra, algunas de ellas parecen reutilizadas como se observa en el ángulo NO del Amb. 4. Del mismo modo, hemos de destacar la construcción de algunos tramos de los muros longitudinales $\mathrm{E}$ y $\mathrm{O}$, con sillares de dimensiones diversas $(0,60 \times 0,35 ; 0,78 \times 0,40 ; 0,65 \times 0,45 \mathrm{~m})$. Su utilización en los muros longitudinales reforzaría la hipótesis reconstructiva que harían recaer en ellos la carga de la cubierta del edificio. En cualquier caso, estos muros funcionarían como zócalo de un segundo nivel de paramento realizado con adobes, cuyos restos han sido constatados de forma evidente en los derrumbes de las construcciones (UE 136).

No hay restos sólidos de pavimentos, y tan sólo se han detectado interfaces de tendencia horizontal sobre las que encontramos los niveles de uso y amortización, por lo que hemos de plantear la existencia de suelos de tierra batida. La forma y consistencia de los muros y la ausencia de restos de escaleras parecerían indicar la existencia de una única planta a nivel del suelo. La cubierta de las 


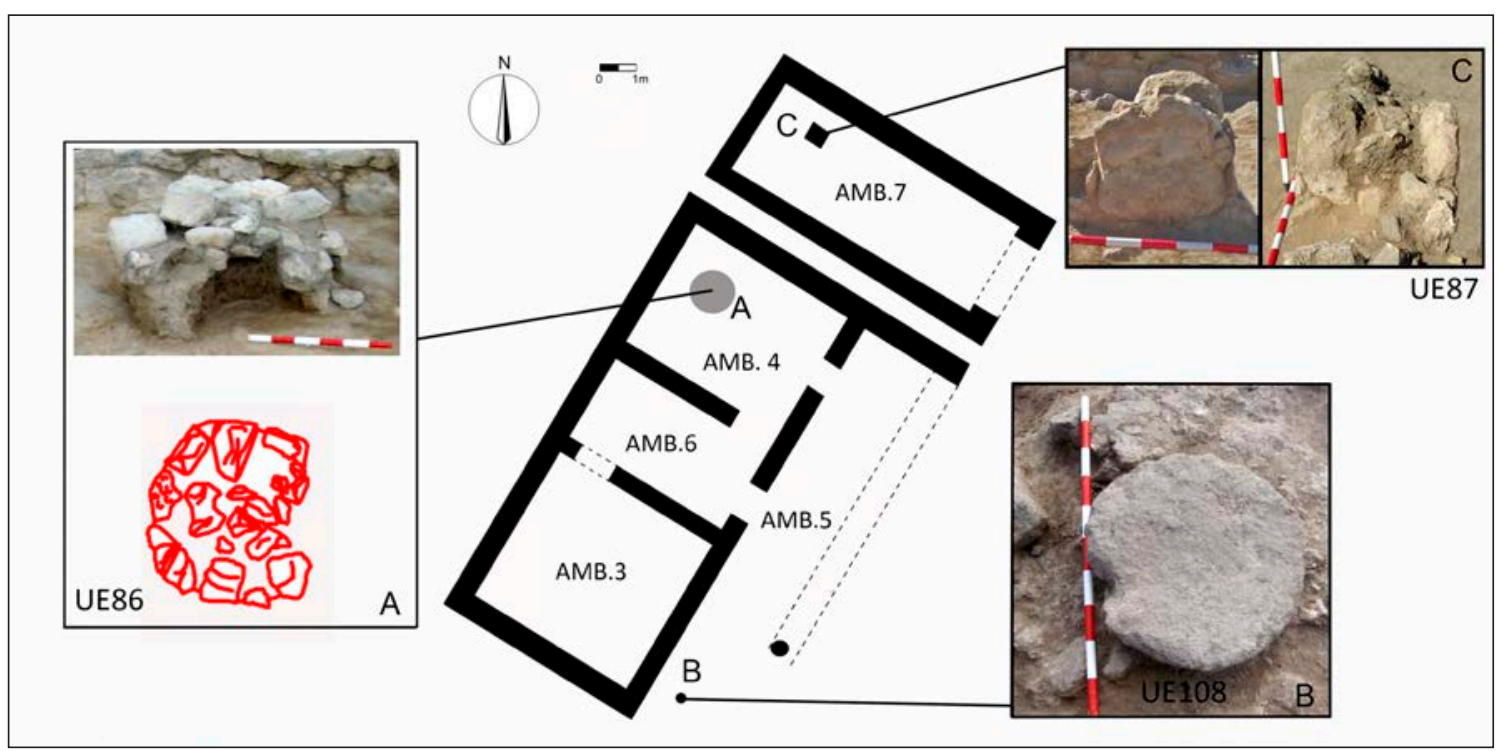

Fig. 5. Restos de estructuras de trabajo y producción de la granja.

estructuras principales (Amb. 3, 4 y 6) sería a dos aguas en sentido O-E con una luz total de $5,76 \mathrm{~m}$, al que se añadiría el porche de 3,37 m de luz (Amb. 5). El edificio septentrional (Amb. 7) estaría cubierto a un agua en sentido S-N salvando una luz de 3,98 m La aparición de tejas en contextos de derrumbe de estas estructuras (Amb. 3, 4, 5), entre las que cabe destacar las de forma plana, señalaría la existencia de una cubierta típicamente romana compuesta por tegulae e imbrices.

Hemos de reseñar la aparición, en la esquina noroeste del Amb. 4, de una estructura de tendencia circular (UE 86) formada por piedras de mediano tamaño trabadas con tierra, por lo que presenta una forma poco regular de 1/1,15 m de diámetro aprox. Su posición estratigráfica demuestra su uso en la Fase 2 del yacimiento, sin que podamos saber de forma fehaciente si también se utilizó en la Fase 1. La interpretación de esta estructura (UE 86) es complicada pues podría tratarse de un hogar, pero no presenta restos evidentes de rubefacción. Asimismo podríamos interpretarlo de forma genérica como un banco circular para el trabajo doméstico, similar a las cercanas, aunque muy anteriores, bases circulares de trabajo de las UUEE constructivas 19 y 18 (VIIA2, VIIIC2) de El Oral (Sala y Abad 2006: 28, fig. 4). O como una base o plataforma para un molino de poca altura como las de los yacimientos ibéricos de Los Villares/Kelin (Caudete de las Fuentes) (Mata 1991; Bonet y Mata 2009: 120, fig. 18) o en el departamento 46 del Tossal de Sant Miquel/Edeta (Llíria) o El Oral (San Fulgencio) (Bonet 1995; Bonet y Mata 2009: 120, fig. 15), entre otros.

Este edificio presenta dos fases de ocupación diferenciadas. La primera (Fase 1) se apoya directamente en la roca madre y se asocia a los niveles fundacionales del siglo I d.C. que definen un edificio de tendencia simétrica con acceso central y dos estancias laterales. La Fase 2 está definida por niveles de pavimentación superpuestos que contienen abundantes restos materiales del siglo III que se asocian a una serie de remodelaciones constructivas que indican cambios de uso y circulación de los espacios: cegamiento del vano situado entre los Amb. 4 y 6 o la elevación de niveles de uso evidentes en el vano de entrada al Amb. 6. Asimismo en esta segunda fase se observan remodelaciones en el porche (Amb. 5) con la aparición de una alineación algo irregular de piedras de gran tamaño escuadradas de 0,35 x 0,50 m (UE 72), en el límite exterior que marcaría el apoyo de las columnas, en cuya fundación se han encontrado fragmentos de pared de cerámicas ARS claras C del s. III.

La organización del espacio habitativo de la granja (Amb. 3, 6 y 4), al menos en su primera fase, parece presentar una cierta simetría con un espacio central de menores dimensiones (Amb. 6: 12,25 $\mathrm{m}^{2}$ ) y dos estancias paralelas y casi simétricas de dimensiones mayores (Amb. 4: 18,11 $\mathrm{m}^{2}$ y Amb.3: 19,49 m²), y que están 
comunicadas con la central que cumpliría funciones de distribuidor. De las tres habitaciones que conforman la estructura habitativa poco podemos decir de las dos estancias meridionales (Amb. 3 y 6), al hallarse prácticamente cubiertas y amortizadas por la ermita (Amb. 2 A-B). Por lo que sólo hemos podido desarrollar una excavación completa del Amb. 4. No obstante, con los datos disponibles se puede realizar una propuesta de organización interna de los espacios y circulación.

El acceso se realizaría desde el porche (Amb. 5), al que se abren dos estancias (Amb. 4 y 6) por sendos vanos. Aunque no hay evidencias irrefutables cabría la posibilidad de que el acceso desde el porche al Amb. 4 fuese posterior, asimilable a la segunda fase constructiva romana bajoimperial, como indican una serie de elementos, por otra parte no concluyentes: los accesos desde el porche (Amb. 5) presentan forma y medidas diferentes, destacando la fuerte irregularidad constructiva que presenta el acceso exterior del Amb. 4, pues sus jambas no están bien alineadas; en la segunda fase constructiva (s. III) el vano que comunica los Amb. 4 y 6 se halla cegado por un muro de piedra, lo que haría imprescindible abrir un acceso directo desde el porche y podría justificar la apertura de éste, aunque es posible que existiera en la fase anterior; además habría que señalar que este tipo de edificios de época augustea o s. I d.C. suelen presentar una marcada simetría, incluso en edificios sin aspiraciones representativas, y esta simetría es evidente en la forma del edificio (espacio central de acceso Amb. 6 y estancias simétricas laterales Amb. 4 y 3), y en este contexto resulta contradictorio el acceso exterior del Amb. 3. Finalmente se podría señalar que la lógica constructiva basada en paralelos histórico/arqueológicos de otras épocas, apuntaría a la construcción de edificios con reducidos vanos exteriores, para minimizar el efecto interior de las temperaturas extremas, en esta zona sobre todo el calor y condiciones exteriores, por lo que podría ser más adecuado tener un único acceso exterior central, como el que se documenta en el Amb. 6. Reiteramos que se trata sólo de hipótesis no concluyentes, por lo que el vano de acceso al Amb. 4 podría ser igualmente de la fase del s. I d.C.

El conjunto presenta un porche de 2,40 m de luz abierto al E (Amb. 5). Esta parte del edificio tendría una doble función: servir de fachada oriental del edificio, dando acceso a las diferentes estancias habitacionales que se sitúan al $\mathrm{O}$, y articular una terraza artificial, creando un área abierta delante del edificio con funciones múltiples, entre ellas las productivas. En su lado meridional la caída natural del terreno, en el que aflora la roca madre, impediría un desarrollo horizontal del pavimento del porche por lo que éste no ocuparía todo el frente oriental del edificio. El hallazgo de los restos de una base de columna de piedra de 0,40 m de diámetro (UE 142) en línea con el final del muro septentrional (UE 14) del Amb. 5 nos permite trazar el límite oriental del porche y la línea

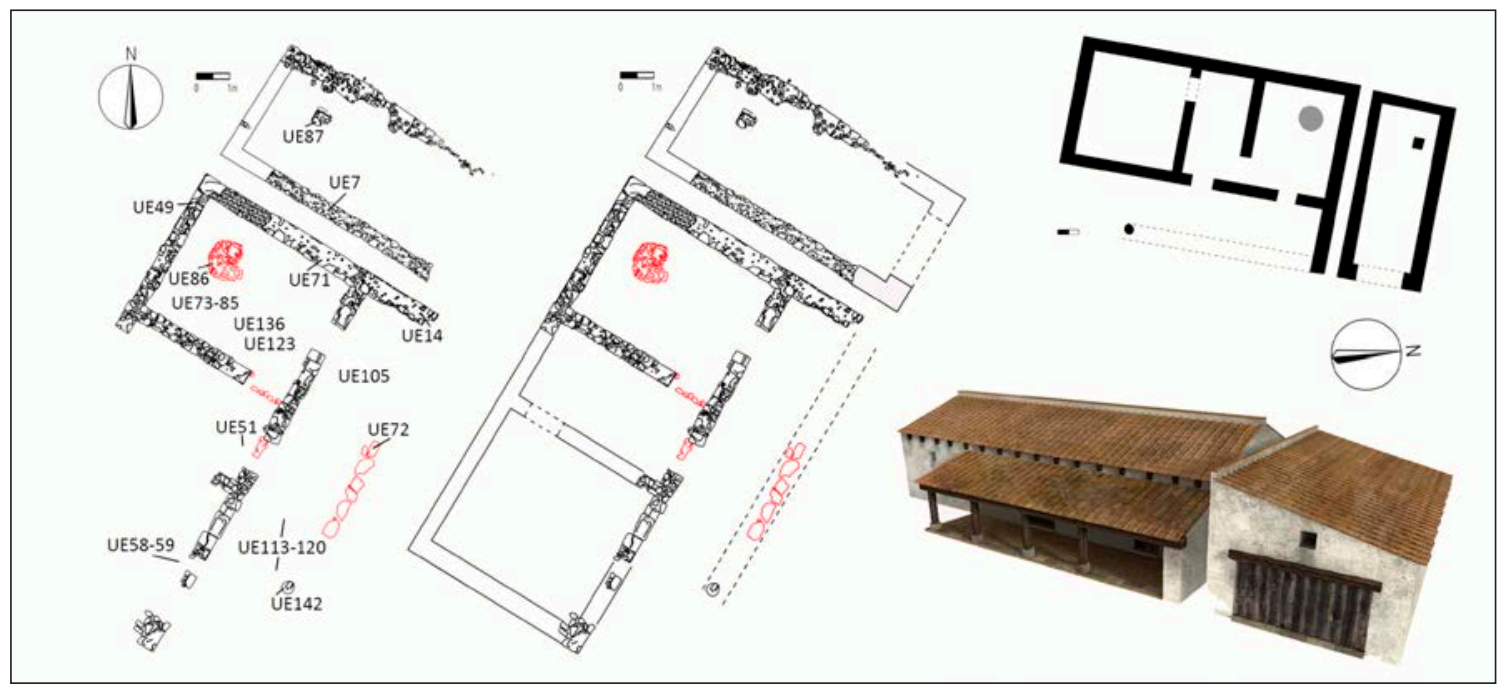

Fig. 6. Granja romana: planta, reconstrucción planimétrica y reconstrucción virtual (realizada por J. Molina y D. Tejerina). 
de aguas del tejado. Si tomamos ambos elementos (UE 14 y UE 142) como extremos del frente del porche podemos proponer la existencia de otras tres columnas en medio, dando un conjunto de cuatro intercolumnios. La ausencia de tambores de columna de piedra o de cuartos de columna de ladrillo podría apuntar a un posible desarrollo de los soportes con base de piedra y alzado de madera, aunque no deja de ser una hipótesis reconstructiva, referente del modelo final de reconstrucción virtual que hemos desarrollado (fig. 6).

Como hemos señalado al norte del edificio y separado tan sólo por 0,65 m se erige otra construcción (Amb. 7) de $3,98 \times 7,83 \mathrm{~m}\left(20,09 \mathrm{~m}^{2}\right)$. Es un espacio absolutamente arrasado del que tan sólo emerge del nivel de pavimentación su muro meridional (UE 7) y una base cuadrada de piedra situada en su interior (UE 87) de 0,47 m de lado. Aunque no tiene relación estratigráfica directa con el resto de construcciones, la coincidencia de las orientaciones, grosor de muros y técnicas constructivas indicarían que formaba parte del conjunto. Dados los escasos datos estratigráficos disponibles y la ausencia de paralelos fiables resulta muy difícil plantear la función de este edificio, aunque al estar separado del resto del conjunto podría apuntarse una utilidad productiva a modo de almacén, cobertizo o establo.

El edificio principal de época imperial, presenta planta rectangular dividida en tres ambientes precedidos de un pórtico en su fachada oriental. La ausencia de instalaciones de transformación especializadas como las cellae uinariae, dolia o torcularia indicarían que la producción de este establecimiento no sería ni el vino o el aceite, o que si ésta existiera sólo podría dirigirse al autoconsumo al carecer de instalaciones de almacenaje y transformación a mayor escala. Aunque no se podrá descartar de forma taxativa dicha producción hasta que no se documente todo el entorno del yacimiento dado que podría darse una producción comercializable (vid u olivo) que se procesase o transformase en instalaciones externas centralizadas. Todo ello junto a la presencia de una piedra de molino (UE 108) (fig. 5) aparecida en el Amb. 5, en un nivel revuelto y por tanto fuera de su contexto original, apuntaría a una producción de cereal y una orientación productiva preferentemente autosuficiente. La base agrícola cerealista de este asentamiento campesino podría verse completada con una pequeña cabaña ganadera que podría alojarse en el Amb. 7, aunque la ausencia de restos óseos no deja mucho margen a los análisis sustanciales o a las propuestas concluyentes en ese sentido. No sería tan arriesgado apuntar a un complementario aprovechamiento de la laguna, junto a la que se encuentra, de cuya pesca tenemos noticias hasta épocas relativamente recientes (s. XVIII).

\section{LA CRONOLOGÍA DEL ASENTAMIENTO CAMPESINO ROMANO DEL CABEZO-CLOT DE GALVANY}

Los materiales más antiguos localizados hasta el momento se datan en época tardorrepublicana y quedan ilustrados por algunos fragmentos de ánfora Dressel $1 \mathrm{de}$ procedencia centroitálica (finales s. II- s. I a.C.), dos fragmentos de cerámica de barniz negro Beoide (ss. II-I a. C.), vajilla ibérica decorada de una fase tardía (s. I a. C.-I d.C.) y, especialmente destacable por su antigüedad, un fragmento de borde de ánfora púnico-ebusitana T-8.1.3.2 (200/190 al 120/100 a.C.). No obstante, no parece que haya una relación directa entre estos materiales y una fase constructiva concreta de la que tengamos constancia. Más bien parecería relacionarse con restos materiales del desmantelamiento de construcciones de una fase anterior ubicada en los alrededores y posiblemente reutilizados en la construcción de la granja romana. Prueba de ello es la reutilización de gran número de piedras de una tonalidad más clara y de mayor tamaño que las demás en distintos ángulos o jambas del edificio. Cabe destacar una gran piedra de forma rectangular almohadillada colocada en el ángulo NO del Amb. 4 (UUEE 49-71) de posible origen precedente al presentar la almohadilla sólo en un lado.

La construcción del edificio se apoya directamente sobre la roca madre y sus niveles fundacionales no ofrecen evidencias cronológicas. No obstante, llama la atención la abundante presencia de cerámica sigillata de cronología augusteo-tiberiana en diversos contextos: sigillata gálica Atlante Forma R2.1 (10 a.C.-15 d.C.); Goudineau 5 (20 a.C.-15 d.C.); un fragmento de sigillata itálica del tipo Conspectus 32 (15-30 d.C.), además de distintos fragmentos de ánfora Dressel 2-4 y Haltern 70. Todo ello podría apuntar a la primera mitad del s. I d.C. como periodo de construcción del conjunto.

En los niveles fundacionales del pavimento del porche (Amb. 5), casi en contacto con la roca madre (UE 105), se halló una moneda de bronce muy deteriorada. Se trata de una moneda de 19-21 mm de diámetro, $3 \mathrm{~mm}$ de grosor y un peso de 5,77 gr., con algunos elementos y restos de leyendas que permitirían proponer que se tratara de semis de posible ceca provincial de posible cronología tiberiana. 
Poblamiento rural en el territorium de Ilici: la granja romana del Cabezo-Clot de Galvany (Elx, alacant)

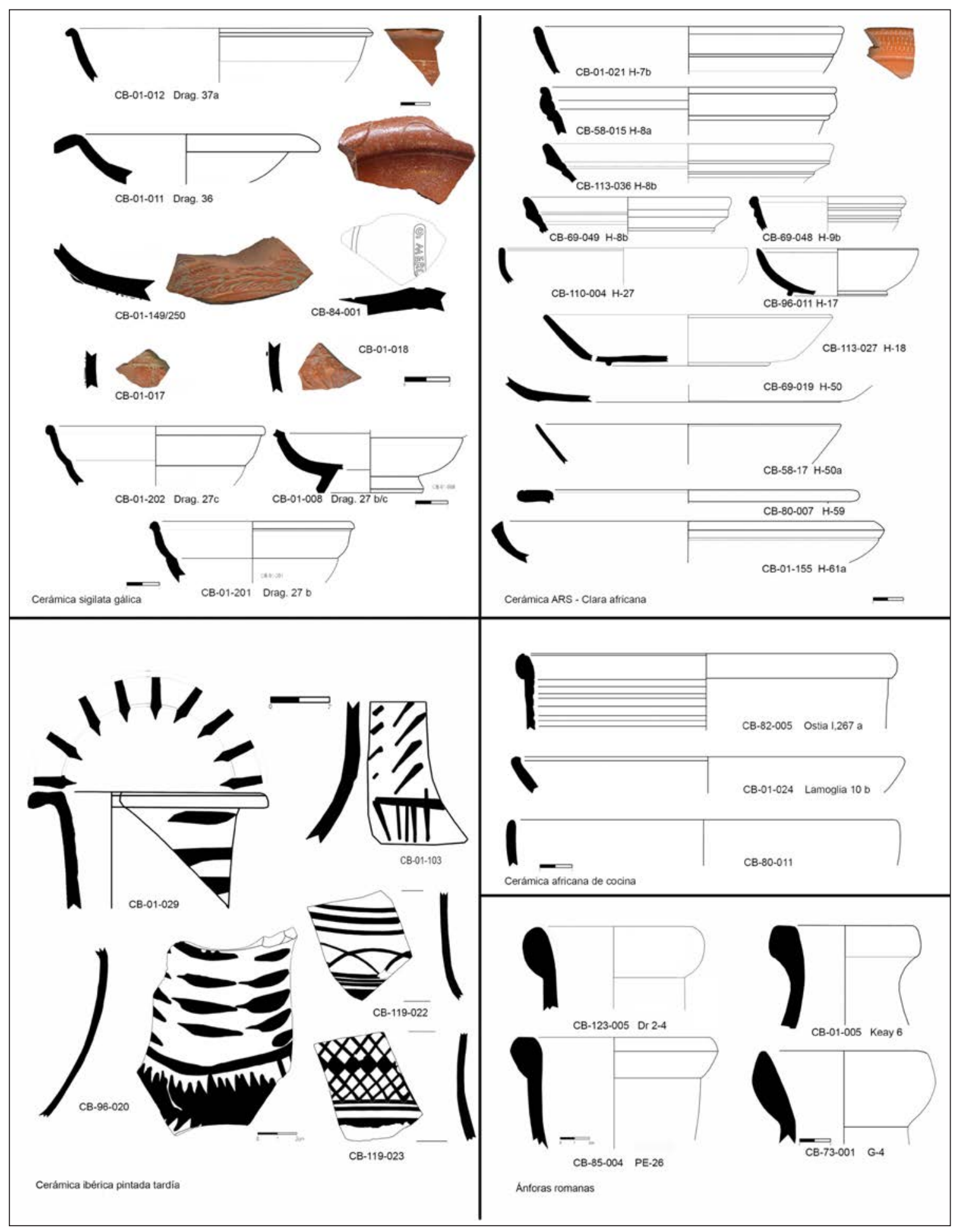

Fig. 7. Selección de cerámicas de época romana. 
No obstante, es mucho más frecuente la presencia de cerámica sigillata gálica de cronología posterior: Dragendorff 18 (15-150); Drag.27b (40-80); Drag. 27c (80-120); Drag. 29 (10-90); Drag. 33 (60-120); Drag. 36 (60-160) o Drag. 37a (60-100). Esta importante presencia de materiales de época flavia y principios del II podría interpretarse como una intensificación de las actividades o del hábitat, o un aumento relativo de las relaciones comerciales y consumo de productos importados. En general las formas gálicas son predominantes, respecto a las itálicas e hispánicas, muchas de ellas decoradas con motivos venatorios, destacando la presencia de un sello del figulus llamado Mercator, presente en los talleres de la Graufesenque (80-120 d.C.). También es mayor la presencia de ánforas del s. I d.C. (Dressel 2-4, Dressel 20, Beltrán II o Gauloise 4) frente a los contenedores del s. I a.C. (Dressel 1), junto a varias Haltern 70 que estarían en una horquilla cronológica intermedia.

Los niveles de uso del Amb. 4 (UE 123) se pueden asimilar al s. I d.C., especialmente entre 20 y 80 d.C., con la presencia de ánforas Dressel 2-4 de pastas catalanas y valencianas, y un fondo de cerámica sigillata hispánica decorada (40-150). No obstante, la presencia de un fondo de cerámica clara africana (ARS) y de cerámicas africanas de cocina, apuntarían a una continuidad de uso hasta época bajoimperial sin hiato o cesura alguna. La continuidad de ocupación parece respaldada por la fuerte y prolongada presencia de cerámicas finas claras barnizadas africanas (ARS) de todas las variantes (especialmente A y C, y residualmente D) y múltiples tipos (Hayes 3, $6,7,8,9,23,31,50 \mathrm{~b}, 59$ o $61 \mathrm{~b}$ ) en distintos niveles del yacimiento.

Finalmente se detecta una serie de niveles de amortización de tierras cenicientas con alta presencia de material orgánico asimilables a basureros de la fase de abandono del yacimiento (UUEE 58-59, 73-85, 113 120 y 51). Sobre ellos se apoyan directamente los niveles de construcción de la ermita de época moderna. En estos niveles de amortización destaca el alto contenido en cerámicas africanas bajoimperiales (ánforas, cazuelas y vajilla de mesa tipo ARS A y C), datables a finales del s. III o el s. IV. La escasa presencia de cerámicas ARS clara D (tipos Hayes 59 (320-420) o H61a (325400) lleva a un periodo comprendido entre el segundo tercio del s. IV y las primeras décadas del s. V el fin de la frecuentación de la zona. Sin embargo, hemos de destacar el carácter absolutamente residual de estas cerámicas
ARS clara D en este yacimiento, cuando en otros yacimientos cercanos como La Picola-Portus Ilicitanus (Santa Pola, Alicante) los niveles de los ss. IV y V son muy potentes y las cerámicas ARS clara D abundantísimas (Molina 2005). Todo ello, junto con la presencia mayoritaria de cerámicas ARS clara C nos llevaría a proponer una fase de abandono definitivo de las estructuras situado entre finales del s. III o principios del IV. Los basureros reseñados (UUEE 58-59, 73-85, 113-120 y 51) presentan una cronología final del s. II- principios del IV por la presencia de cerámicas Hayes 59 (320420). A todo ello habría que añadir la práctica ausencia de ánforas bajoimperiales, excepción hecha de un fragmento del tipo Keay 6, cuando tanto en La Alcudia como en el Portus Ilicitanus son absolutamente frecuentes y abundantes. De todas formas no hay, en general, abundancia de restos anfóricos lo que parecería acrecentar el carácter eminentemente autosuficiente del asentamiento. Aunque es difícil realizar estadísticas comparadas entre yacimientos, pues no disponemos de la publicación de esos datos en otros yacimientos agrícolas cercanos, habríamos de señalar que tan sólo hemos hallado seis fragmentos de borde de ánfora romana. Esta cifra es relativamente pequeña para una superficie de niveles romanos excavada de $250 \mathrm{~m}^{2}$ y una media de $0,75 \mathrm{~m}$ de profundidad, dando un resultado aproximado de los $190 \mathrm{~m}^{3}$ de volumen exhumado, para un periodo de tres siglos.

A modo conclusivo podríamos señalar que se han podido definir dos momentos de ocupación del yacimiento en época romana:

- FASE 1: fase romana fundacional cuya cronología es difícil de precisar, pero que abarcaría el s. I d.C., con una mayor probabilidad o intensificación del hábitat en el último tercio de este siglo. Esta fase tiene continuidad durante toda la época altoimperial para sufrir remodelaciones profundas en el s. III.

- FASE 2: identificada con fuertes remodelaciones constructivas: amortización de vanos; elevación de umbrales y niveles de uso; construcción de nuevas estructuras en el porche; construcción de una estructura de planta circular (UE 86) en el ambiente 4. Estas transformaciones se asocian a materiales del s. III, aunque los niveles de uso presentan restos con cronologías que alcanzan el s. IV, y muy residualmente la segunda mitad del s. IV o principios del V.

- FASE 3: Construcción de una ermita en uso durante el s. XVII. 


\section{LA OCUPACIÓN DEL TERRITORIO DE ILICI Y SUS ÁREAS MARGINALES: VILLAE Y ASENTA- MIENTOS CAMPESINOS/GRANJAS}

Las estructuras romanas de El Cabezo-Clot de Galvany, de planta secuencial rectangular con tres estancias contiguas abiertas a un porche en su fachada oriental, destacan por su extremada sencillez, articulación simple y no canónica, difícilmente asimilable al modelo itálico de villa. La existencia de una estructura rectangular adyacente y semiabierta, podría interpretarse como un área de almacenamiento, establo o cobertizo, pero la total ausencia de estructuras o evidencias materiales de transformación de la producción (dolia, torcularia, etc.), impediría plantear procesos de tratamiento de la producción para su comercialización. De hecho la única evidencia productiva es un simple molino de forma cónica hallado en contextos secundarios. Todo ello hace evidente la escasez de elementos asimilables al modelo de villa romana: asentamiento de pequeñas dimensiones y con dependencias adyacentes para el trabajo externo (porche y cobertizo); planta rectangular sin patio central; orientación económica preferente autosuficiente sin estructuras de transformación. Paralelamente hallamos elementos constructivos que presentan una cierta continuidad con la arquitectura ibérica, aunque en época altoimperial: tipo de planta secuencial; zócalos de piedra en la base del edificio con refuerzos de sillares en los ángulos; alzados de adobe; construcción de porche exterior donde desarrollar parte de las actividades habitativas y productivas en espacios exteriores, y utilización de estructuras externas no integradas (Amb. 7). Pero al mismo tiempo hallamos elementos constructivos típicamente romanos: utilización de morteros de cal en los zócalos o muros conservados; refuerzo constructivo perimetral con sillares algo irregulares en los muros externos longitudinales; planta con cierta tendencia simétrica con estancia central de menores dimensiones, a modo de posible distribuidor con dos estancias a cada lado, y, especialmente, uso de cubiertas típicamente romanas de tegulae e imbrices.

Han pasado dos siglos desde la conquista romana y el proceso de romanización ya se encuentra muy avanzado en el territorio de Ilici, por lo que resulta difícil seguir a Vitrubio $(2,1)$, cuando indica que este tipo de construcciones no canónicas se deben exclusivamente a variedades o particularismos provinciales. En realidad, creemos que la explicación de la aparición de este tipo de estructuras poco canónicas deben buscarse de forma combinada en el ámbito cultural y en el social: continuidad de tradiciones indígenas conviviendo con elementos constructivos romanizados y origen socialmente humilde de sus habitantes. Contemplamos la posible filiación ibero-romana de sus habitantes, al tiempo que se pone de manifiesto el utilitarismo de estas construcciones carentes de estructuras o formas de expresión externa del rango social: estancias de representación pública (atrios, tablinum o peristilos); articulaciones axiales o programas decorativos, elementos inútiles en el contexto social bajo de sus habitantes. No hallamos, pues, estructuras asimilables a la domus, como por el contrario sí se observa en contextos cercanos como la vivienda de la Illeta dels Banyets (El Campello) (Olcina-Pérez-Soler 1997: 38) o la conocida domus 5F de Ilici, por ejemplo.

En cualquier caso cabe plantarse si el asentamiento campesino de El Cabezo-Clot de Galvany es un caso único, una excepción o presenta paralelos. Podríamos acumular decenas de paralelos acudiendo a ejemplos cercanos del ámbito ibérico, necesariamente más antiguos, como los del El Oral (Abad y Sala 1993; 2009), El Puig d'Alcoi (Grau y Segura 2013), La Bastida de les Alcusses (Bonet y Vives-Ferrándiz 2011; Vives-Ferrándiz 2013) o en los territorios de Edeta y Kelin (Mata et al. 2009). En cualquier caso este asentamiento campesino podría asimilarse al modelo de casa ibérica monofocal simple (Grau 2013: 61),

Paralelamente en el ámbito romano no son extraños los ejemplos de estructuras habitativas de este tipo como son las denominadas row-type houses que J.T. Smith (1997) cataloga en regiones del noroeste europeo. Entre las estructuras lineales y menos simétricas destacan las de menor tamaño (Smith 1997: 102-105) muchas con tan sólo dos o tres estancias, y en otras ocasiones incluso de una sola cella, que en su conjunto harían referencia a granjas o pequeños establecimientos campesinos, absolutamente alejados del concepto canónico de villa o domus. Cabe destacar por la gran proximidad formal con el caso que nos ocupa de algunas pequeñas row-houses del norte de Francia, interpretadas como residence of a conjugal family, como son los casos de de Dury, L'Etoile, Harbonnières, Vaux, Kempten-Loja 1 o Rheinfelden-Herten-Warmbach (Smith 1997: 102-103, fig. 29), todas ellas de tres estancias y dimensiones similares al asentamiento de El Cabezo-Clot de Galvany.

En Britania D. Perring (2002) presenta viviendas de planta circular propias de la Edad del Hierro, es decir, de raigambre claramente indígena, que perduran entre los ss. II al IV d.C. Al mismo tiempo encontramos una variada gama de casas/granjas denominadas romano-británicas de 
los tipos strip buildings y row-type town houses que presentan disposición lineal y alargada de sus espacios, sin habitaciones centrales distribuidoras (tipo atrio) y por su organización funcional (Molina 2013: 136-137, fig. $n^{\circ}$ 8). Destacan por sus paralelos formales con la granja de El Cabezo-Clot de Galvany los asentamientos tipo strip buildings de London One Poultry con tres estancias (Burch et al. 1997; Perring 2002: 59-60, fig. 13a) o las row type houses de Dorchester Collinton Park (Drew y Selby 1937; Perring 2002: 64, fig. 16a) con porche de entrada o la pequeña casa con estancia de recepción de Silchester 17,4 (Fox y St John Hope 1898; Perring 2002: 64, fig. 16a) que presenta cuatro estancias.

La estructura que tradicionalmente se ha tomado como base de la articulación espacial de las viviendas romanas ha sido la domus, una residencia organizada en torno a patios centrales (atrios y peristilos), que a su vez es la base de referencia de la parte habitativa (pars urbana) del modelo clásico de ocupación del espacio rural que son las villae rusticae. No hallamos esta estructura en el asentamiento campesino de El Cabezo-Clot de Galvany, ni esa forma de estructurar los espacios. Como se puede observar en la bibliografía arqueológica más reciente, cada vez son más frecuentes los hallazgos de viviendas alejados del modelo de la domus y la creciente aparición de asentamientos de producción agrícola no asimilables a las villae rusticae. ¿Qué son estas estructuras? ¿Cómo hemos de denominarlas?

Las referencias de las fuentes sobre estos habitáculos y viviendas marginales son escasas e infrecuentes y sólo ocasionalmente hallamos denominaciones del tipo tugurium, casa (Ovidio, Metam. 8, 628; Apuleyo, Metam., 4, 12; Tito Livio III,13,10; III,26,9; V,53,8; XLII,34,2), cenacula (Festus-Paulus, IX; Gelio 15, 1), insula (Heródoto 1, 180; Estrabón 16, 1, 5; Apiano 8, 128; Vitrubio II, 3, 63-65; Estrabón, XVI, 2, 23) o uillula. Las características básicas de estas viviendas son sus reducidas dimensiones, la baja calidad de los materiales empleados y su estructuración secuencial (carente de los característicos patios centrales, atrios o peristilos, de la domus), o con pasillos o porches que permiten el acceso y distribución a sus dependencias. En el ámbito rural cabría destacar su carácter aislado y el uso de cubiertas poco resistentes como el barro o la paja, aunque en áreas donde el proceso de romanización se encuentra muy avanzado conviviendo con la utilización de cubiertas de teja. En todos los casos este tipo de viviendas se asocian a colectivos de extracción social baja y condición poco más que miserable (Molina 2013: 128-129).
El asentamiento de El Cabezo-Clot de Galvany presenta elementos formales más cercanos a estos modelos marginales que a las villae rusticae, por lo que es necesario hacer precisiones terminológicas. Tal y como hemos defendido en otros ámbitos (Molina 2009: 41), consideramos que el término villa se asocia principalmente a estructuras rurales de carácter agrícola-mercantil, dirigidas fundamentalmente a la producción agraria comercializable (aceite y vino principalmente), por ello presentan cellae uinariae o torcularia. La villas en muchos casos se asocian a grupos sociales de carácter elevado por lo que sus estructuras habitativas (pars urbana) contienen espacios de representación social y disfrute del ocio (atrios, peristilos, balnea, decoraciones lujosas, jardines o grandes comedores), verdaderas urbs in rure. Las grandes villae rusticae cumplirían a la perfección los requisitos básicos del canon vitruviano de utilitas, uenustas y firmitas (Vitruvio 1,3,2), y muchas de ellas recogerían los elementos básicos que según Vitruvio conformaban la arquitectura como la ordenación, disposición, euritmia, simetría y ornamento.

Entonces cómo habremos de calificar los yacimientos que no cumplen estos requisitos, caracterizados por sus pequeñas dimensiones y la orientación económica preferentemente autosuficiente. La historiografía reciente que se ha ocupado del tema ha convenido en denominarlos como asentamientos campesinos (établissements ruraux según la denominación la historiografía francesa), asimilable a lo que sería una granja. Frente a la definición de villa podríamos definir estos asentamientos campesinos como núcleos de orientación económica preferentemente autosuficiente, con una base de producción cerealista ( $\sin$ cellae uinariae o torcularia) con escaso margen de comercialización de excedentes, que presentan estructuras habitativas unifamiliares, de pequeño tamaño, carentes de espacios de representación social (atrios, peristilos, balnea o decoraciones lujosas), por lo que presentan planta secuencial y extremadamente funcional.

A la luz de la historiografía tradicional, podría parecer que este tipo de estructuras son una excepción de áreas periféricas del imperio, pero las investigaciones sobre el poblamiento rural romano de la última década ponen de manifiesto la abundancia, si no el predominio de este tipo de asentamientos campesinos, granjas o uillulae. Estructuras semejantes y en la misma época son muy frecuentes en territorios de la Galia Transalpina: Lorraine (Georges-Leroy et al. 2013); Aquitania septentrional (Gandini et al. 2013: 77-78) y meridional (Colleoni et al. 
2013: 221); Narbonense, entre Nimes y Lattes (Bermond et al. 2013: 93-95); Narbonense oriental y los Alpes marítimos (Bertoncello y Lautier 2013: 206-208), o en el N de Galia (La Picardie y La Flandre septentrional) (Bayard y De Clercq 2013: 168-169). En Hispania hallamos ejemplos de granjas de pequeñas dimensiones y características semejantes en Lusitania, en los territoria de Ossonoba (Teichner 2013: 143-144) y Emerita Augusta (Sánchez Barrero 2013: 297) o en la Tarraconense, como vemos en los territorios de Gerunda y Emporiae (Plana y De Prado 2013: 57), el Ager Tarraconensis (Prevosti et al. 2013: 105-106), el territorio de Dianium (Grau y Molina 2013: 63), o los de Ilici, Lucentum y Allon (Frías 2010). Por no mencionar los crecientes ejemplos documentados en territorios propiamente itálicos como el ager Cosanus y otros territorios de Etruria (Carandini et al. 2002); valle del Potenza (Percossi et al. 2006) o el valle del Tiber (ampliamente atestiguado en las innumerables publicaciones derivadas del Tiber Valley Project de la British School at Rome) (Molina 2013:136-137).

Parece que las estructuras de época romana de El Cabezo-Clot de Galvany se ajustarían a este modelo de granja/asentamiento campesino, coherentemente con el elemento característico de los territorios en los que se asienta: su marginalidad. Y no parece que pueda calificarse como casual la confluencia de tres elementos característicos de este asentamiento: su ubicación marginal en el territorio, su proyección agropecuaria autosuficiente y los escasos vínculos formales y culturales con el modelo itálico de villa (Grau y Molina 2013). La constatación de estos tres hechos nos invita a proyectar una serie de cuestiones e hipótesis que podrían orientar futuras investigaciones en el territorio ilicitano: ¿cómo hemos de interpretar esta ocupación marginal? ¿Es casualidad que este asentamiento campesino se desarrolle a partir de la época augusteo-tiberiana? ¿Qué importancia tiene la baja adscripción social de sus habitantes o su posible filiación cultural ibero-romana, en cualquier caso no oligárquica? Estas cuestiones las formulamos como base de una hipótesis que apuntaría a una posible ocupación de estos territorios marginales ilicitanos a partir de la saturación de los territorios centrales periurbanos de Ilici, tras la segunda asignación colonial de época augustea (Alföldy 2003: 42). El área central con mejores tierras sufriría una creciente presión demográfica fruto de la sortitio reflejada la tabula de Ilici (forma) (Chao et al. 1999; Mayer y Olesti 2001; 2002; Olesti 2005). La fundación colonial supondría un fuerte impacto en el paisaje de Ilici que se manifestaría de forma inmediata en el entorno centuriado de la urbs, todavía apreciable en la estructura del parcelario agrícola actual. Todo ello nos permite plantear, siquiera a modo de hipótesis, un desplazamiento de poblaciones socialmente desfavorecidas a territorios aledaños, $\mathrm{y}$ en este caso menos propicios para la explotación agropecuaria. Se podría proponer la asignación preferente de lotes coloniales a los veteranos de guerra, sin descartar a otras poblaciones locales, pero parecería lógico plantear un traslado o ubicación de grupos marginados de las asignaciones coloniales o, incluso desplazados por éstas, hacia áreas periféricas como el humedal de El Clot de Galvany.

Esta ocupación de zonas periféricas, que habría que seguir investigando en otras áreas periurbanas de la ciuitas, podría asociarse a la primera fase de ocupación del asentamiento campesino de El Cabezo-Clot de Galvany en el cambio de Era o la primera mitad del s. I d.C. No obstante, la pervivencia durante más de tres siglos nos indicaría de una saturación estructural, no coyuntural, del espacio de la pertica ilicitana y la ocupación de las áreas periféricas. Este asentamiento y el modelo de explotación de poblaciones dispersas campesinas, no sería excepcional, desarrollando un ciclo vital plurigeneracional que sería la prueba de su adecuada implantación en el terreno. El grupo campesino que se estableció en este asentamiento muestra un enraizamiento en el lugar y una dinámica en su ocupación con una duración y complejidad semejante a la que se podría identificar en cualquier asentamiento rural de larga perduración, con momentos iniciales, desarrollo y reformas y perduración durante prácticamente toda la época romana.

Asimismo hemos de destacar la existencia de indicadores claros de la incorporación de este tipo de enclaves a redes de poblamiento y marcos organizativos de la economía y los intercambios que exceden el propio autoconsumo y el funcionamiento autónomo. La presencia regular de restos bienes de consumo como las ánforas y la vajilla fina de mesa del tipo terra sigillata o cerámicas claras ARS serían la prueba de su incorporación a un marco de relaciones de intercambio, lo que permitiría matizar la idea de marginalidad del asentamiento, descartando absolutamente su aislamiento socioeconómico. Sin duda, este asentamiento hubo de gestionar un excedente con el que participar de los intercambios, necesariamente menor que el de los enclaves orientados a la agricultura comercial o de plantación, que lo integra en una lógica económica de más amplio alcance. Por ello no sería descartable, dado que la granja carecía de almazaras y lagares, que 
este establecimiento produjera de forma secundaria productos que precisaran ser transformados (vid u olivo), pero cuyo procesamiento se realizara en establecimientos externos mayores y centralizados.

En el estado actual de la investigación parece difícil proponer patrones de asentamiento fiables para las áreas periféricas de la colonia de Ilici. Aunque son muchas las publicaciones sobre el territorio ilicitano hemos de señalar que tanto la $u r b s$, de la que ni tan siquiera se conoce el foro, como su territorium adolecen de investigaciones en profundidad y proyectos de investigación consolidados que permitan realizar análisis científicamente consistentes, por lo que hemos de mantenernos en el terreno de las hipótesis. Observamos una ocupación menor en época tardorrepublicana con cronologías y tipos de asentamiento difíciles de precisar. A partir de la época augustea se manifiesta un fuerte aumento de la ocupación territorial especialmente en el área centuriada en la que detectamos numerosos asentamientos claramente vinculados al reparto colonial, algunos del tipo villa. En esta época se cuadruplica el número de asentamientos detectados, gran parte de ellos ex novo, con una elevada proporción (2/3) de establecimientos tipo villa o con evidencias de producciones comercializables de vino y, parece que preferentemente, aceite. Las investigaciones de Frías Castillejo (2010: 192-193) muestran la frecuente aparición de restos de dolia o torcularia aparecidas en las prospecciones del área periurbana de Ilici (Canyada Joana, Candela, El Charco, Villa Petraria, El Campet o L'Arquet, entre otras). Paralelamente observamos la existencia de una significativa proporción de yacimientos que no parecen responder al modelo de villa (1/3 aprox.), sino a lo que denominamos granjas o asentamientos campesinos, entre los que se encuentra el yacimiento que nos ocupa. Todo ello sin entrar en la hipotética ocupación de territorios del medio y alto Vinalopó, con supuestas tramas centuriadas (Cortadella et al. 1998; Moratalla 2001), hasta el momento difíciles de demostrar de forma definitiva.

En conclusión, el asentamiento campesino de El Cabezo-Clot de Galvany se encuentra en la periferia del territorium de Ilici, junto a un humedal con tierras pobres y poco aptas para la agricultura, que debemos considerar terrenos marginales. Un área que tras la época romana ha estado históricamente deshabitada y sólo se volvió a ocupar a partir del s. XVII, con el crecimiento demográfico de época moderna, como muestra la construcción de la ermita. El elemento característico de los territorios en los que se asienta la granja de El Cabezo-Clot de Galvany es su carácter periférico, hecho que junto a su simplicidad estructural, funcionalidad y orientación preferentemente autosuficiente sustentan la probable extracción baja de sus habitantes. De ahí la importancia de este asentamiento campesino ilicitano que nos permite abrir líneas de investigación novedosas, complementarias a las tradicionales, estancadas y repetitivas fórmulas de análisis espacial del área centuriada. Sirva esta investigación para animar a la comunidad científica a renovar las perspectivas de análisis de los territoria romanos, especialmente en el paradigmático caso ilicitano, y para impulsar la renovación metodológica y las excavaciones en el propio núcleo urbano de Ilici.

JaIme Molina VIDAL Dpt. Prehistòria, Arqueologia, $\mathrm{H}^{\mathrm{a}}$ Antiga, Filologia Grega i Filologia Latina Universitat d'Alacant jaime.molina@ua.es

\section{NOTA}

1. Investigación desarrollada en el marco de los proyectos de investigación del MINECO (Ministerio de Economía y Competitividad), HAR2012-37003-C03-02; HAR2012-32881, Ministerio de Cultura (IPCE/PERUSA 07-11) y Universidad de Alicante (ACIE08-07).

\section{BIBLIOGRAFÍA}

ABAD, L.; SALA, F. (1993): El poblado ibérico de El Oral (San Fulgencio, Alicante), Serie de Trabajos Varios del S.I.P., 90 , Valencia.

ABAD, L.; SALA, F. (2009): La arquitectura y el urbanismo de El Oral (San Fulgencio, Alicante). Un ejemplo de asimilación de la arquitectura fenicia y púnica, Phönizisches und punisches Städtewesen (S. Helas, D. Marzoli eds.), Mainz, 499-514.

BAYARD, D.-DE CLERCQ, W. (2013): Organisation du peuplementet habitatsen Gaule du Nord, confrontation de deux exemples régionaux. La Picardie et la Flandre septentrionale, Paysages ruraux et territoires dans les cités de l'Occident romain. Gallia et Hispania (J. L. Fiches, R. Plana, V. Revilla, coord.), Montpellier, 161-180.

BERMOND, I.; BUFFAT, J.; FICHES, P.; GARMY, P.; PELLECUER, CHR.; POMARÈDES, H.; RAYNAUD, CL. (2013): Nîmes en Narbonnaise, essai sur la géographie des territorires à l'échelle de la cité, Paysages ruraux et territoires dans les cités de l'Occident romain. Gallia et Hispania (J. L. Fiches, R. Plana, V. Revilla, coord.), Montpellier, 83-98. 
BERTONCELLO, FR.; LAUTIER, L. (2013): Formes et organisation de l'habitat en Narbonnaise orientale et dans les Alpes Maritimes (cités de Fréjus, Antibes, Vence et Briançonnet), Paysages ruraux et territoires dans les cités de l'Occident romain. Gallia et Hispania (J. L. Fiches, R. Plana, V. Revilla, coord.), Montpellier, 195-212.

BINFORD, L. (1981): Behavioral archaeology and the «Pompeii Premise», JAR 37 (3), 195-208.

BONET, H. (1995): El Tossal de Sant Miquel de Lliria. La antigua Edeta y su territorio, Valencia.

BONET, H.; MATA, C. (2009): El urbanismo ibérico en el área valenciana. El oppidum como centro de poder y reflejo del tejido social, Tarraco: construcción i arquitectura d'una capital provincial romana, actes del congrés Internacional en homenatge a Theodor Hauschild, Butlletí Arqueològic, $\mathrm{V}, 31,107-144$.

BONET, H.; VIVES-FERRÁNDIZ, J. (2011): La Bastida de les Alcusses. 1928-2011, Valencia

BURCH, M.; LEES, D.; HILL, J.; ROWSOME, P.; JONES, S.; TREVEIL, P. (1997): Number 1 Poultry-the Main Excavation: Roman Sequence, Archaeologia 8, 127-136.

CARANDINI, A.; RICCI, A. (Ed.) (1985): Settefinestre: Una Villa schiavistica nell'Etruria romana, Modena.

CARANDINI, A.; PAPI, E. (2006): Palatium e Sacra via II. L'età tardo-repubblicana e la prima età imperiale (fine del III secolo a.C. - 64 d.C.), Bollettino di Archeologia 59-60, Roma.

CARANDINI, A.; CAMBI, F.; CELUZZA, M. (2002): Paesaggi d'Etruria: Valle dell'Albegna, Valle d'Oro, Valle del Chiarone, Valle del Tafone : progetto di ricerca italo-britannico seguito allo scavo di Settefinestre, Roma.

CHAO, J.; MESA, J. F.; SERRANO, M. (1999): Un nuevo bronce hallado en La Alcudia, Actas del Congreso Internacional Ciudades privilegiadas en el Occidente romano, Sevilla, 417-424.

COLLEONI, F.; PETIT-AUPERT, C.; SILliÈRES, P. (2013): Paysages ruraux et formes de miseen valeur des campagnes en Aquitaine méridionale (cités d'Auch, d'Eauze et de Lectoure), Paysages ruraux et territoires dans les cités de l'Occident romain. Gallia et Hispania (J. L. Fiches, R. Plana, V. Revilla, coord.), Montpellier, 213-222.

CORTADELLA, J.; OLESTI, O.; PRIETO, A. (1998): El estudio de las centuriaciones en la península ibérica: progresos y límites, Arqueología Espacial 19-20, 429-442.

DREW, C. D.; SELBY, K. C. (1937): First Interim Reporton the Excavations at Colliton Park, Dorchester 1937-8, Procs Dorset Nat. Hist. and Archaeol. Soc. 59, 1-14.

FERNÁNDEZ VEGA, P. A. (2003): La casa romana, Madrid.

FRÍAS, C. (2010): El poblamiento rural de Dianium, Lucentum, Ilici y la ciudad romana de la Vila Joiosa (siglos II a.c.-VII d.c.). Bases para su estudio. Alicante.

FOX, G. E.; ST JOHN HOPE, W. H. (1898): Excavations on the Sitenof the Roman City at Silchester, Hants, in 1897, Archaeologia 56 (2), 229-250.
GANDINI, C.; DUMAIS, FR.; LAÜT, L. (2013): Paysages économiques du territoire des Bituriges Cubes: approche comparée de trois modes d'occupation du sol, Paysages ruraux et territoires dans les cités de l'Occident romain. Gallia et Hispania (J. L. Fiches, R. Plana, V. Revilla, coord.), Montpellier, 67-82.

GEORGES-LEROY, M.; LAFFITE, J. D.; FELLER, M. (2013): Des paysages ruraux antiques contrastés dans les cités des Leuques et des Médiomatriques : effet de source ou répartition différentielle des établissements dans l'espace rural?, Paysages ruraux et territoires dans les cités de l'Occident romain. Gallia et Hispania (J. L. Fiches, R. Plana, V. Revilla, coord.), Montpellier, 181-194.

GRAHAME, M. (2000): Reading Space: Social Interaction and Identity in the Houses of Roman Pompeii, BAR Int. Ser. 886, Oxford.

GRAU, I. (2013): Unidad doméstica, linaje y comunidad: estructura social y su espacio en el mundo ibérico (ss.VI-I a.C.), De la estructura doméstica al espacio social. Lecturas arqueológicas del uso social del espacio (S. Gutiérrez, I. Grau, eds.), Alicante, 57-76.

GRAU, I.; MOLINA VIDAL, J., (2013): Diversité territoriale et modes d'explotation des paysages ruraux du sud de la Tarraconaise (II siècle av. J.-C.- II siècle apr. J.-C., Paysages ruraux et territoires dans les cités de l'Occident romain. Gallia et Hispania (J. L. Fiches, R. Plana, V. Revilla, coord.), Montpellier, 59-66.

GRAU, I.; SEGURA, J. M. (2013): El oppidum ibérico de El Puig d'Alcoi. Asentamiento y paisaje en las montañas de la Contestania, Alcoi.

GUTIÉRREZ-CORTINES, C.; GRIÑÁN, M. (1994): La devoción en el espacio: las ermitas en los territorios de las órdenes militares, Imafronte 10, 51-60.

HOFFMANN, A. H. (1979): L'Architettura, en Pompei 79, Racolta di studi per il decimonono centenario dell'eruzione vesuviana (a cura di F. Zevi), Napoli, 97-118.

MATA, C. (1991): Los Villares (Caudete de las Fuentes, Valencia): origen y evolución de la Cultura Ibérica, Serie de Trabajos Varios del S.I.P. 88, València.

MATA, C.; MORENO, A.; PÉREZ, G.; QUIXAL, D.; VIVES-FERRÁNDIZ, J. (2009): Casas y cosas del campo: hábitat agrícola y estructura social en los territorios de Edeta y Kelin (siglos V-III a.n.e.), Arqueomediterrània 11, L'espai domèstic i l'organització de la societat a la protohistòria de la Mediterrània occidental (Ier mil-lenni aC), Actes de la IV Reunió Internacional d'Arqueologia de Calafell (Calafell - Tarragona, 6 al 9 de març de 2007) (M. C. Belarte, ed.), Calafell, 143-152.

MOLINA VIDAL, J. (1997): La dinámica comercial romana entre Italia e Hispania Citerior (ss.II a.C.-II d.C.), Alicante.

MOLINA VIDAL, J. (2005): La cetaria de Picola y la evolución del Portus Ilicitanus (Santa Pola, Alicante), III Cong. Int. de Est. Históricos. El Mediterráneo: la cultura del mar y la sal (J. Molina Vidal, M. J. Sánchez Fernández, eds.), Elche, 95-112. 
MOLINA VIDAL, J. (2009): La villa romana: de las fuentes escritas a la creación del concepto histórico, Actes del Simposi: Les vil·les romanes a la Tarraconense, (V. Revilla, J. R. González Pérez, M. Prevosti Monclús, eds.), Barcelona, vol. I, 37-48.

MOLINA VIDAL, J. (2013): Utilitas frente a venustas: viviendas populares de la antigua Roma, De la estructura doméstica al espacio social. Lecturas arqueológicas del uso social del espacio (S. Gutiérrez, I. Grau, eds.), Alicante, 127-140.

MAYER, M.; OLESTI, O. (2001): La sortitio de Ilici. Del documento epigráfico al paisaje histórico, DHA 27/1 109-130.

MAYER, M.; OLESTI, O. (2002): Le tirage au sort des lots coloniaux: la sortitio d'Ilici, Atlas historique des cadastres d'Europe II (M. Clavel-Lévêque, A. Orejas, eds.), Luxembourg, Dossier 1T 4A-6B

MORATALLA, J. (2001): Restos de catastros romanos en el Medio Vinalopó y unos apuntes sobre Aspis, Alquibla, 7, 551-582.

OLCINA, M.; PÉREZ JIMÉNEZ, R. (2003): Lucentum: la ciudad y su entorno, Canelobre 48, 89-120.

OLESTI, O. (2005): La sortitio de Ilici. Un ejemplo de precisión agrimensora, Vocabulaire téchnique des arpenteurs romains (J. Y. Guillaumin et al., eds.), Besançon, 47-61.

PERCOSSI, E.; PIGNOCCHI, G.; VERMEULEN, F. (eds.) (2006) I siti archeologici della Vallata del Potenza, Ancona.

PERRING, D. (2002): The roman house in Britain, London-New York.

PLANA, R.; DE PRADO, G. (2013): Les modalités du peuplement d'époque romaine dans la partie central de l'Empordà: de l'oppidum d'Ullastret aux civitates d'Emporiae et de Gerunda, Paysages ruraux et territoires dans les cités de
l'Occident romain. Gallia et Hispania (J. L. Fiches, R. Plana, V. Revilla, coord.), Montpellier, 49-58.

PREVOSTI, M.; LÓPEZ, J.; FIZ, I. (2013): Paysage rural et formes de l'habitat dans l'ager Tarraconensis, Paysages ruraux et territoires dans les cités de l'Occident romain. Gallia et Hispania (J. L. Fiches, R. Plana, V. Revilla, coord.), Montpellier, 99-108.

SALA, F.; ABAD, L. (2006): Arquitectura monumental y arquitectura doméstica en la Contestania, Lucentum XXV, 23-46.

SÁNCHEZ BARRERO, P. D. (2013): El paisaje agrario romano en las proximidades de Augusta Emerita, Paysages ruraux et territoires dans les cités de l'Occident romain. Gallia et Hispania (J. L. Fiches, R. Plana, V. Revilla, coord.), Montpellier, 293-302.

SMITH, J. T. (1997): Roman villas. A study in social structure, London-New York.

TEICHNER, F. (2013): El territorium de Ossonoba (Lusitania): economía agrícola y economía «marítima», Paysages ruraux et territoires dans les cités de l'Occident romain. Gallia et Hispania (J. L. Fiches, R. Plana, V. Revilla, coord.), Montpellier,137-148.

TOMEI, M. A. (1995): Domus oppure lupanar? I materiali dello scavo Boni della casa repubblicana a ovest dell'arco di Tito, MEFRA CVII, 549-619.

VIVES-FERRÁNDIZ, J. (2013): Del espacio doméstico a la estructura social en un oppidum ibérico. Reflexiones a partir de la Bastida de les Alcusses, De la estructura doméstica al espacio social. Lecturas arqueológicas del uso social del espacio (S. Gutiérrez, I. Grau, eds.), Alicante, 95-110. 